\title{
Idiopathic sclerochoroidal calcifications: Case report, metabolic causes and differential diagnosis
}

\author{
Calcificações esclerocoroidais idiopáticas: relato de caso, \\ causas metabólicas e diagnóstico diferencial
}

Maria del Mar Prieto del Cura ${ }^{1}$ https://orcid.org/0000-0003-4076-9204

Marina Sastre-lbáñez ${ }^{1}$ https://orcid.org/0000-0003-0640-894X

María José Crespo Carballés ${ }^{1}$ https://orcid.org/0000-0001-5743-0499

\begin{abstract}
Sclerochoroidal calcifications (SC) are a rare and benign ocular condition characterized by yellow-white irregular subretinal lesions usually found in the supero-temporal arcade of the midperipheral fundus in middle-aged elderly men. We present a clinical case of a 79- year-old patient who during a fundus examination presented raised whitish nodules in the supero-temporal arcade in the right eye. After performing optical coherence tomography, ultrasound, ocular computed tomography and laboratory analysis, she was diagnosed with idiopathic sclerochoroidal calcifications The pathogenesis of sclerochoroidal calcifications remains unclear but systemic conditions should be discarded. It is important to distinguish sclerochoroidal calcifications from other conditions such as tumors.

Keywords: Calcinosis/diagnosis; Choroid diseases/diagnosis; Scleral diseases/diagnosis; Idiopathic sclerochoroidal calcifications; Diagnosis, differential; Metabolic diseases
\end{abstract}

\section{RESUMO}

Calcificações esclerocoroidais (SC) são uma condição ocular rara e benigna caracterizada por lesões sub-retinianas irregulares amarelo-brancas, geralmente encontradas na arcada superotemporal do fundo médio-periférico em homens idosos de meia-idade. Apresentamos um caso clínico de uma paciente de 79 anos que durante exame de fundo apresentou nódulos esbranquiçados elevados na arcada superotemporal do olho direito. Após realizar tomografia de coerência óptica, ultra-sonografia, tomografia computadorizada ocular e análise laboratorial, ela foi diagnosticada com calcificações esclerocoroidais idiopáticas

A patogênese das calcificações esclerocoroidais permanece incerta, mas as condições sistêmicas devem ser descartadas. É importante distinguir calcificações esclerocoroidais de outras condições, como tumores.

Descritores: Calcinose/diagnóstico; Doenças da coróide/diagnóstico; Doenças da esclera/diagnóstico; Diagnóstico diferencial; Calcificações esclerocoroidais idiopáticas; Doenças metabólicas

${ }^{1}$ Hospital Universitario Infanta Leonor, Madrid (Spain)

The authors declare no conflict of interest

Received for publication 24/3/2020 - Accepted for publication 6/7/2020. 


\section{INTRODUCTION}

$\mathbf{I}$ diopathic sclerochoroidal calcifications (SC) are commonly found in white men between 50 and 80 years of age. Described as yellowish-white plaques located in the supero-temporal arcade in the mid-peripheral retina, under retinal layers, in both eyes. Approximately 40 to $80 \%$ of cases are bilateral and asymmetric. ${ }^{(1)}$ with an average of two locations per eye. ${ }^{(2)}$ They are usually a casual finding; visual disorders have rarely been described although they may be associated with choroidal neovascular membranes and neurosensory detachments. ${ }^{(3)}$

Autofluorescence and the appearance of the lesion with ultrasound and tomography are useful for its diagnosis. ${ }^{(4)}$ These plaques may simulate tumors ${ }^{(1,2)}$ and can lead to misdiagnosis especially with choroidal osteomas. ${ }^{(4)}$ Metastases, amelanotic melanomas, nevus, idiopathic choroiditis or intraocular lymphomas ${ }^{(1,5)}$ should be excluded.

This process can be associated with systemic metabolic disorders in relation to abnormal calcium-phosphorus metabolism or renal tubular syndromes with hypokalemic metabolic alkalosis. ${ }^{(6)}$ It is a diagnosis of exclusion, it is important to study these electrolyte disorders. ${ }^{(1,7)}$

\section{Clinical case}

A 79-year-old woman who reported myodesopsias in both eyes (OU) for 1 month. Corrected visual acuity was 20/25 in BE. Biomicroscopy was normal and intraocular pressure was $18 \mathrm{mmHg}$ in OU. Fundoscopic examination revealed raised whitish nodules measuring $7 \mathrm{~mm}$ in height and $2.5 \mathrm{~mm}$ in width in the upper temporal arcade in the right eye. (Figure 1)

Ultrasound calcifications were found in the left eye, these were not visible in ophthalmoscopy. (Figure 2) Ultrasound B-mode examination showed an hyper-echogenic plaque at the level of the sclera and choroid with posterior acoustic shadow with a peak of high reflectivity at the site of the lesion followed by posterior low amplitude peaks (wide angle kappa) in the A- mode.

Visual fields were normal (Full Field 81, Humphrey), orbital tomography revealed nonspecific calcifications in the posterolateral wall of OU. (Figure 3) Angiography showed relative hypofluorescence in the arterial phase and hyperfluorescence in the venous phase that intensified in later phases

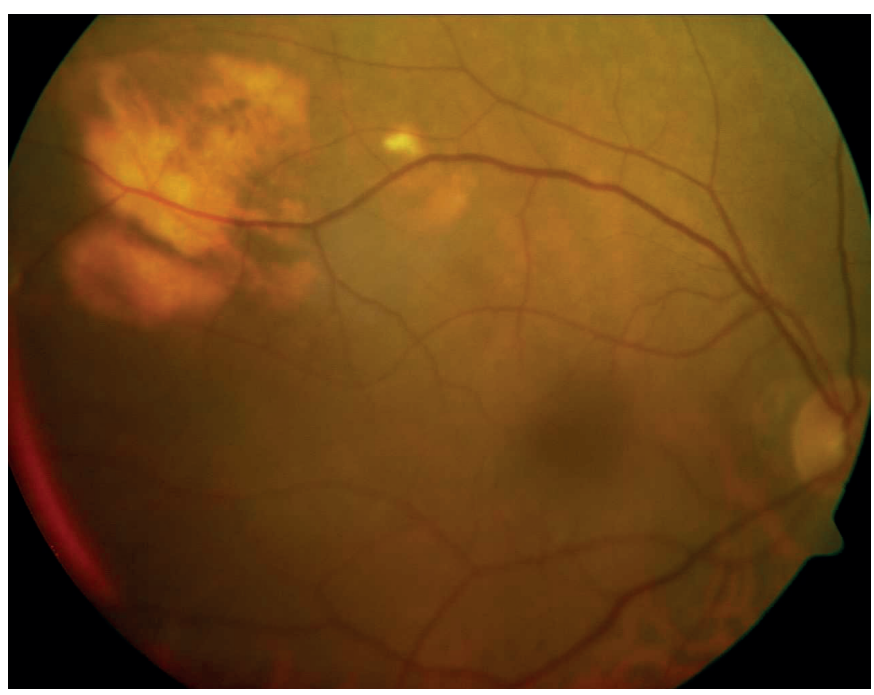

Figure 1: Retinography showing raised whitish nodules in the upper temporal arcade of the right eye

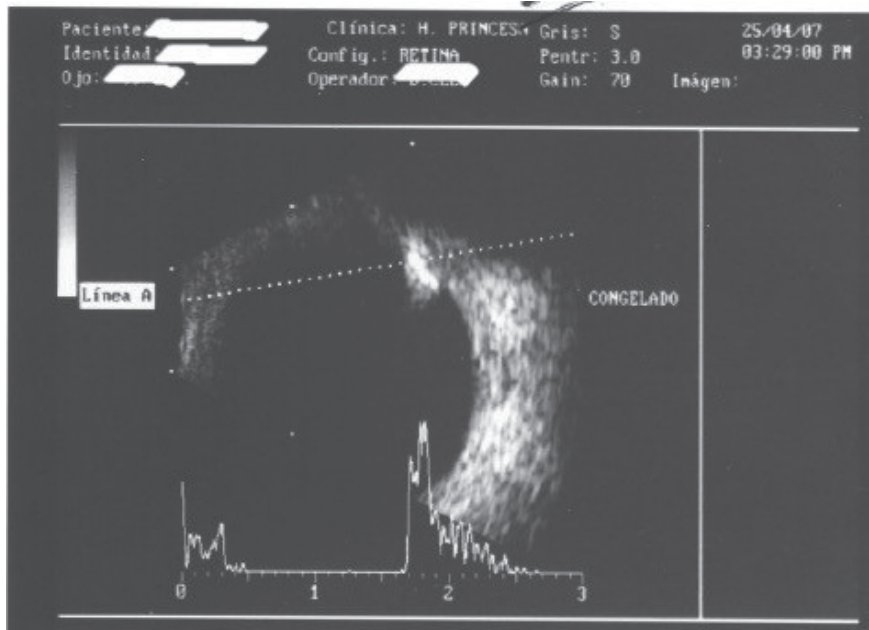

Figure 2: Ultrasound: posterior calcifications in the left eye

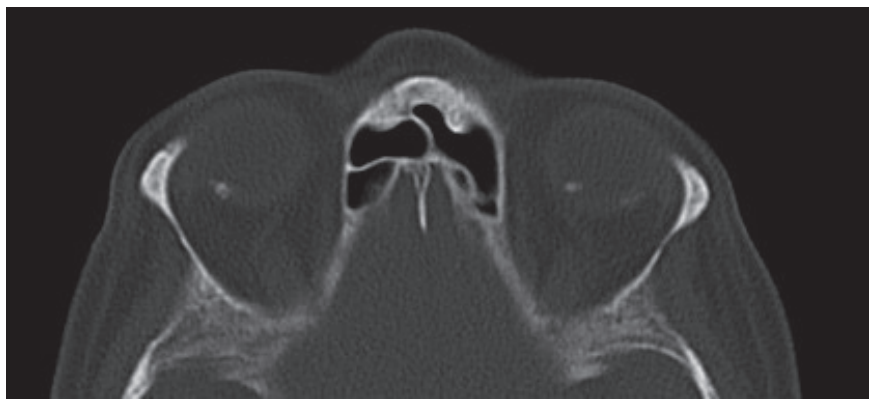

Figure 3: Orbital tomography with nonspecific calcifications in the posterolateral wall of both eyes

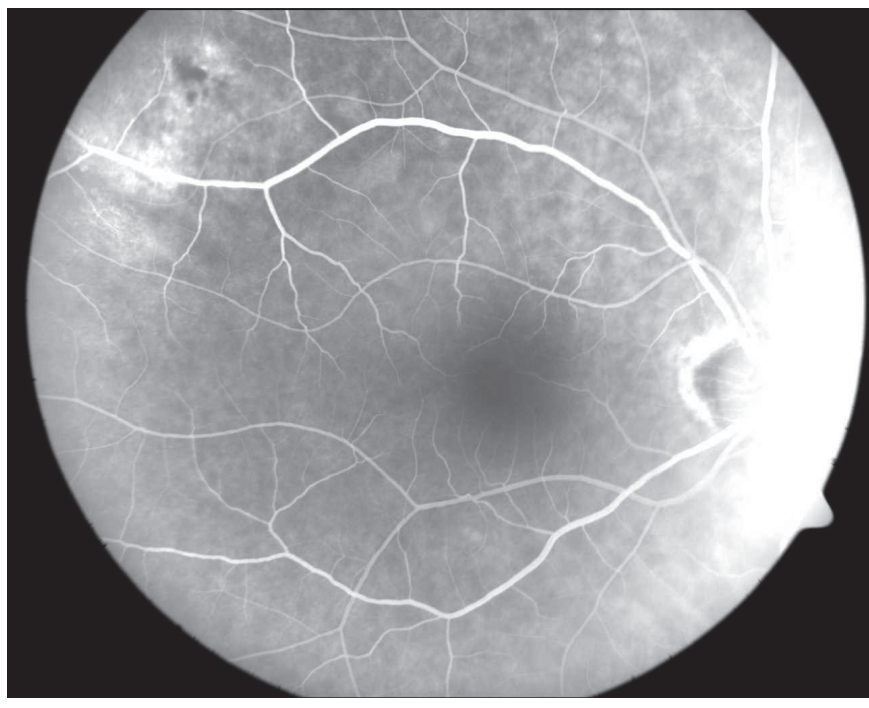

Figure 4: Angiography with hyperfluorescence of the lesion in the venous phase

(Figure 4). With indocyanine green angiography hypofluorescence was observed in vascular filling phases with posterior hyperfluorescence (Figure 5). No evidence of choroidal neovascularization was detected.

The patient has personal history of hiatal hernia and renal cysts, long-term hypertension treated with metoprolol and lovastatin for hypertriglyceridemia. We performed haematological and hormonal studies where the first determination of PTH was 87.36 $\mathrm{pg} / \mathrm{ml}$ (normal limits between), with total calcium of $9.9 \mathrm{mg} / 1$ 


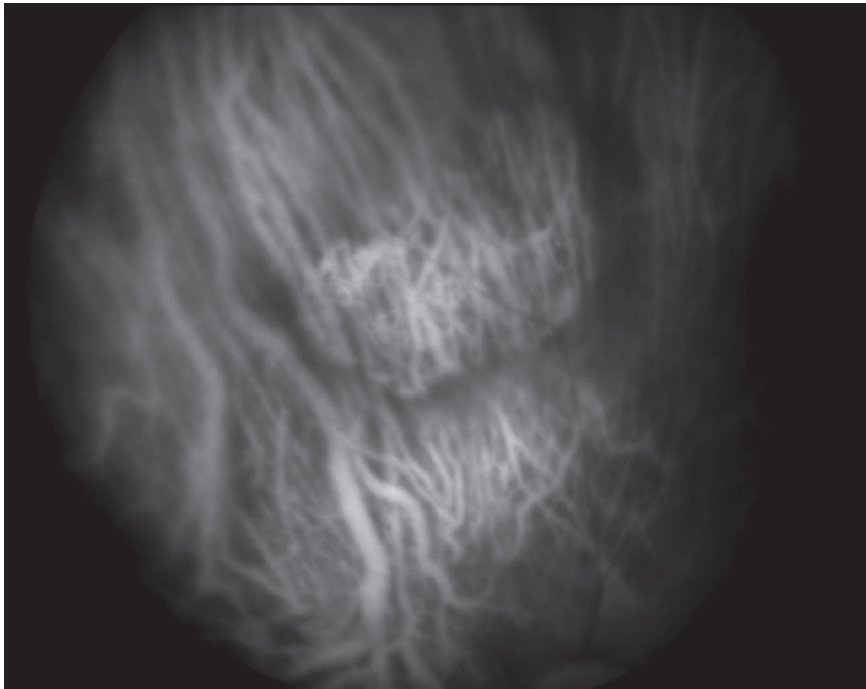

Figure 5: Indocyanine green angiography with late hyperfluorescence of the sclerochoroidal calcification

(corrected with albumin of $9.6 \mathrm{mg} / \mathrm{ml}$ ). $\mathrm{dl} *$ ). Vitamin D levels of $16.41 \mathrm{ng} / \mathrm{ml}$ (lower cut-off point of $20 \mathrm{ng} / \mathrm{ml}$ ) were observed. After administration of active metabolites of vitamin D PTH levels normalized.

\section{DiscusSION}

Sclerochoroidal calcifications have been described in the literature as a rare process found in old patients. They have been misdiagnosed and treated as tumors in the past, ${ }^{(4)}$ in fact the finding of idiopathic calcification was initially attributed in the literature to choroidal osteomas in older patients but were later recognized to be slcerochoroidal calcifications in $1991 .^{(5)}$ The ophthalmoscopic characteristics of these lesions vary from choroidal osteomas, although its colour is similar, osteomas usually affects young patients, is unifocal, large and usually locates juxtapapilar or in the papillomacular region. ${ }^{(5)}$

Choroidal metastases are another entity that must be differentiated. These normally have bigger dimensions, are well defined and are often associated with serous detachments. ${ }^{(5)}$ The echogenic characteristics are also different.. They may also simulate inflammations such as choroidal granulomas or choroiditis.

The deposition of calcium in ocular structures can lead to bone formation (ossification) or to calcium salts precipitation (calcification). ${ }^{(2,4,5)}$ Choroid and scleral calcification can be classified as metastatic, dystrophic and idiopathic. There are multiple systemic causes related to abnormal calcium or phosphate metabolism disorders that can lead to sclerochoroidal calcifications, those that do not exist in these systemic associations are classified as idiopathic. ${ }^{(2,7)}$ (Table 1)

Table 1

Causes of precipitation of calcium salts in ocular structures ${ }^{(2,6)}$

Metastatic: Metabolism of calcium or phosphate disorders with deposit of calcium salts in healthy tissue

Parathyroid gland disorders:

Diseases due to deposits of calcium pyrophosphate (pseudogout)

\author{
Hyperparathyroidism \\ Pseudohyperparathyroidism \\ Pseudo hypoparathyroidism \\ Primary hypercalcemia \\ Hypophosphatemia \\ Disorders related to Vitamin D \\ Vitamin D intoxication \\ Cholecaliciferol intoxication \\ Chondrocalcinosis \\ Kidney disorders \\ Primary tubular syndromes with hypokalemic metabolic alkalosis. \\ Bartter syndrome \\ Gitelman syndrome \\ Chronic renal failure \\ Sarcoidosis
}

\section{Dystrophic: Normal metabolism of calcium or phosphate with deposit of calcium salts in abnormal tissue}

Ocular trauma

Chronic intraocular inflammation

Coats disease

Degeneration senile de la sclera

Choroidal tumors:

Retinoblastoma

Choroidal hemangioma

Astrocytic hamartoma

Choroidal Nevus

Phthisis bulbi

Congenital eye deformations

Idiopathic: Normal metabolism of calcium or phosphate with deposit of calcium salts in normal tissue

\footnotetext{
* formula Ca: Total calcium + $(0.8 \times(4-A / b))$
} 
The first determination of PTH in our patient was higher than normal with a total calcium determination within normal limits. This finding, together with decreased levels of Vitamin D and the subsequent normalization of PTH after administration of active metabolites of vitamin D suggests vitamin D deficiency (described in up to $25 \%$ of elderly patients in Northern countries). ${ }^{(7)}$ Hyperparathyroidism and hypervitaminosis D were ruled out.

Pseudohypoparathyroidism is characterized by the lack of response of the kidney to PTH stimulation and normally affects children. ${ }^{(7)}$ Hypocalcemia, hyperphosphatemia, together with decreased urinary phosphate excretion is characteristic of the genetic subtypes of this condition. In our patient, calcium and phosphorus determinations were normal (inorganic phosphorus: $4.6 \mathrm{mg} / \mathrm{dl})$, as well as urinary phosphate excretion $(627 \mathrm{mg} / 1$ of phosphorus in $24 \mathrm{~h}$ urine).

Another entity associated with sclerochoroidal calcifications is the pseudogout. Deposition of calcium pyrophosphate crystals in tendons, synovium, cartilage and ligaments are found. The patient had history of hip osteoarthritis but this is an infrequent manifestation of pseudogout. ${ }^{(8)}$

Bartter's syndrome and Gitelman's syndrome are two rare conditions that can associate sclerochoroidal calcifications. Both are autonomic recessive ion transport disorders $;$ of the nephron. Hypokalemic metabolic alkalosis with normal blood pressure is characteristic. $^{(8)}$ The first occurs in childhood along with growth retardation and the second in adolescence (associated with severe hypomagnesemia). The patient did not present any of these characteristics (advanced age, normal potassium, magnesium and chlorine levels, together with essential arterial hypertension).

Those associated with senile changes are considered idiopathic. It has been speculated that the chronic traction of the oblique muscles causes calcium to deposit near its insertions. ${ }^{(9)}$ Once the electrolyte disorders presented were discarded, we classified the findings as idiopathic.

It is important early diagnose of sclerochoroidal calcifications to avoid misdiagnosis and non-useful treatments.

\section{REFERENCES}

1. Shields JA, Shields CL. CME review: sclerochoroidal calcification: the 2001 Harold Gifford Lecture. Retina. 2002;22(3):251-61.

2. Kim M, Pian D, Ferrucci S. Idiopathic sclerochoroidal calcification. Optometry. 2004;75(8):487-95.

3. Leys A, Stalmans P, Blanckaert J. Sclerochoroidal calcification with choroidal neovascularization. Arch Ophthalmol. 2000;118(6):854-7.

4. Cooke CA, McAvoy C, Best R. Idiopathic sclerochoroidal calcification. Br J Ophthalmol. 2003;87(2):245-6.

5. Sivalingam A, Shields CL, Shields JA, McNamara JA, Jampol LM, Wood WJ, et al. Idiopathic sclerochoroidal calcification. Ophthalmology. 1991;98(5):720-4.

6. Shields CL, Hasanreisoglu M, Saktanasate J, Shields PW, Seibel I, Shields JA. Sclerochoroidal calcification: clinical features, outcomes, and relationship with hypercalcemia and parathyroid adenoma in 179 eyes. Retina. 2015;35(3):547-54.

7. Honavar SG, Shields CL, Demirci H, Shields JA. Sclerochoroidal calcification: clinical manifestations and systemic associations. Arch Ophthalmol. 2001;119(6):833-40.

8. Pott's JT Jr. Diseases of the parathyroid gland and other hyper- and hypocalcemic disorders. In: Harrison's principles of internal medicine. 17th ed. New York: Mcgraw-Hill ; 2008. p .2377-416.

9. Cogan DG, Kuwabara T. Focal senile translucency of the sclera. Arch Ophthalmol. 1959;62(4):604-10.

\section{Corresponding author:}

Marina Sastre-lbáñez

marinasastre@yahoo.es

Gran Vía del Este, 80, 28031 Madrid

Tel: 0034911918000 